\title{
Synergistic neighborhood relationships with travel behavior: An analysis of travel in 30,000 US neighborhoods
}

\author{
Carole Turley Voulgaris \\ University of California, Los Angeles \\ carole.turley@gmail.com
}

\author{
Evelyn Blumenberg \\ University of California, Los Angeles \\ eblumenb@ucla.edu
}

\section{Kelcie Ralph}

Rutgers, The State University of New Jersey

kelcie.r@gmail.com

\author{
Brian D. Taylor \\ University of California, Los Angeles \\ btaylor@ucla.edu
}

\author{
Anne Brown \\ University of California, Los Angeles \\ aebrown0316@ucla.edu
}

Abstract: A now substantial body of literature finds that land use and urban form have a statistically significant, albeit relatively modest, effect on travel behavior. Some scholars have suggested that various built-environment characteristics influence travel more in concert than when considered in isolation. Yet few previous studies have combined built-environment measures to create holistic descriptions of the overall character of neighborhoods, and fewer still have related these neighborhoods to residents' travel decisions. To address this gap in the literature, we develop a typology of seven distinct neighborhood types by applying factor analysis and then cluster analysis to a set of 20 variables describing built-environment characteristics for most census tracts in the United States. We then include these neighborhood types in a set of multivariate regression models to estimate the effect of neighborhood type on the travel behavior of neighborhood residents, controlling for an array of personal and household characteristics. We find relatively little variation in the number of daily trips among neighborhood types, but there is substantial neighborhood variation in both person miles of travel and mode choice. Travel by residents of one particular neighborhood type is notably distinguished from all others by a very low number of miles traveled, little solo driving, and high transit use. However, this neighborhood type is found almost exclusively in just a few very large metropolitan areas, and its replicability is uncertain.

\section{Article history:}

Received: August 18, 2015

Accepted: October 4, 2015

Available online: August 11,

2016

Data availability: http://www.

its.ucla.edu/publication/

synergistic-neighborhood-

relationships-with-travel-be-

havior-an-analysis-of-travel-in30000-u-s-neighborhoods/.

Copyright 2016 Carole Turley Voulgaris, Brian D. Taylor, Evelyn Blumenberg, Anne Brown, and Kelcie Ralph http://dx.doi.org/10.5198/jtlu.2016.840

ISSN: 1938-7849 | Licensed under the Creative Commons Attribution - Noncommercial License 3.0

The Journal of Transport and Land Use is the official journal of the World Society for Transport and Land Use (WSTLUR) and is published and sponsored by the University of Minnesota Center for Transportation Studies. 


\section{Introduction}

Individual and household travel behavior decisions are intimately related to the built environment. While these relationships between travel and the built environment are complex and nuanced, they are important to people in deciding where to live, work, and shop, and to business owners deciding where to locate. They are also important to policymakers who plan and control land uses and build and operate transportation systems.

The characteristics of the built environment can be described in terms of measures such as population or employment density; the form and scale of built environment; the prevalence of specific facilities, amenities, or businesses; and the diversity of such facilities, amenities, and businesses. But rather than considering each of these characteristics separately, household decision-makers are likely influenced by how the confluence of these built environment characteristics combine to create a place. A neighborhood's overall character or type-including its boundaries - is not an objective determination. Nevertheless, one can describe many salient neighborhood characteristics systematically and empirically. This paper does just that. It describes our use of quantitative methods to develop a typology of neighborhoods and then the use of these neighborhood types as a framework for analyzing travel behavior. While there is an extensive literature on the relationship between travel and the built environment, the analysis described here is unique in its coupling of national travel survey data with a neighborhood typology for the entire United States. Through this approach, we seek to answer the question of how the synergistic character of neighborhoods relates to how much their residents travel and by which mode.

\section{The built environment, neighborhood types, and travel behavior}

Many planners use words beginning with "d" to refer to characteristics of the built-environment. This convention began with Cervero and Kockelman (1997), who identified 3 Ds: density, diversity, and design. Ewing and Cervero (2010) added two more: destination accessibility and distance to transit. These $\mathrm{D}$ variables are broadly defined and have been measured in different ways. In general, studies relating these variables to travel behavior have found most aspects of travel behavior, such as trip frequency (or trip generation), to be more influenced by socioeconomic characteristics than by built-environment characteristics (Ewing and Cervero 2010; Cervero and Kockelman 1997), with the exception that average trip length is more influenced by the built environment (Ewing and Cervero 2010; Cervero and Kockelman 1997).

Other studies have gone beyond single measures of characteristics of the built environment and employed quantitative analytical methods to describe and classify neighborhood types. Several methodological issues associated with classifying neighborhoods have been addressed in these previous studies. Among these is the definition of a neighborhood, which can be highly subjective. Something approaching a consensus among researchers is the establishment of a standard of using census tracts as proxies for neighborhoods, both because the general scale of tracts and neighborhoods are thought to coincide and out of analytical convenience and data availability (Chow 1998; Leigh and Lee 2005; Lin and Long 2008; Mikelbank 2011; Vicino 2008).

There exists an array of statistical techniques for systematically grouping things into categories using multi-dimensional data. Among these, cluster analysis is a useful tool that has been applied to neighborhood classification. With respect to classifying neighborhoods, Lin and Long (2008) perform a cluster analysis using a set of 64 variables, including variables describing both the built environment and demographic characteristics of neighborhood residents, such as race and income. The researchers apply their analysis to the entire United States and find significant differences in travel behavior among neighborhood types. However, their neighborhood types are defined in part based on the demographic 
characteristics of the people living in them and not solely in terms of the physical characteristics of the place. Given that travel behavior is strongly influenced by the socioeconomic characteristics of travelers, apart from the environments within which they live, work, study, and play, it is very difficult to untangle the physical and social influences on travel in their work.

Classifying neighborhoods in terms of both their physical characteristics and the socioeconomics of the people who live in them is useful for descriptive purposes, as Lin and Long (2008) did, but doing so greatly complicates the understanding of cause and effect. Further, given the very large number of variables that can be used to describe neighborhoods, their relationships with one another, and the requirement that all variables in a cluster analysis be normalized to a similar scale, many neighborhood classification studies use another statistical technique called factor analysis as a first stage to reduce a large number of descriptive variables to a smaller number of factors, and then use the resulting factors as inputs to a cluster analysis (Chow 1998; Li and Chuang 2009; Shay and Khattak 2007; Song and Knaap 2007; Song and Quercia 2008; Vicino 2008).

Song and Knaap (2007) employ factor analysis followed by cluster analysis to classify neighborhoods in the Portland, Oregon, metropolitan area. The study uses factor analysis to reduce a set of 21 variables to a set of eight factors. From these factors, the researchers use cluster analysis to identify six neighborhood types. Shay and Khattak (2007) use factor analysis and then cluster analysis to classify neighborhoods in the Charlotte, North Carolina, metropolitan region. The study identifies seven clusters, which happen to arrange themselves spatially into a pattern that suggests concentric zones of classical theories of urban geography (Burgess 1925; Hoyt 1939). Shay and Khattak (2007) do not find neighborhood type to be associated with any significant difference in household auto ownership and finds only the city center neighborhood type to be associated with a significant difference in trip generation.

The built environment is expected to influence travel patterns by altering the availability and relative utility of travel by various modes. There are, however, problems with viewing the causal arrow as running exclusively (or even primarily) from the built environment to travel behavior, since households can self-select into neighborhoods that match their travel preferences. If we do not include attitudes and preferences in our analysis (and in this study, we do not), we may overstate the true effect of the built environment on travel behavior. Under some conditions we may also understate the magnitude of the effect (Chatman 2013; Næss 2014). Fortunately, considerable scholarly effort has already been expended to elucidate the self-selection issue. In general, scholars find that the estimated effect of the built environment diminishes somewhat, but remains important, when attitudes and preferences are included in their models (Cao, Mokhtarian, and Handy 2009; Ewing and Cervero 2010; Handy, Cao, and Mokhtarian 2005; Mokhtarian and Cao 2008; Zhou and Kockelman 2008).

Levine, Inam, and Torng (2005) have argued that, if certain neighborhood types are undersupplied, policies that accommodate or encourage the development of those neighborhoods may serve to modify travel behavior through residential self-selection, in addition to any direct influence that the built environment itself may have on travel. By classifying neighborhoods throughout the entire United States, we can determine not only what types of neighborhoods are associated with particular travel choices but also the relative availability of such neighborhoods to the individuals and households who might wish to select into them.

We describe below our effort to combine the nationwide geographic analysis employed by Lin and Long (2008) with a focus on the physical characteristics of neighborhoods only-excluding characteristics of the people who live, work, and travel in them. Like Song and Knapp (2007) and Shay and Khattak (2007), we use factor analysis and cluster analysis in concert to characterize physical and transportation system characteristics of nearly every census tract in the United States into a set of neighborhood/ 
district types. Our goal with this exercise is to separate land use/urban form and socioeconomic factors in describing and understanding travel behavior.

\section{Data and methodology}

We combine in our analysis data from three sources, which apply to census tracts across the United States: (1) data taken directly from the Environmental Protection Agency (EPA) Smart Location Database (Ramsey and Bell 2014); (2) data derived from the EPA Smart Location Database (Ramsey and Bell 2014), either by combining multiple Smart Location Database variables or aggregating densities computed at the census block group level to the census tract level; and (3) data taken directly from the 2010 Decennial United States Census (United States Census Bureau 2010). The variables used in our factor analysis and their sources are summarized in Table 1.

Table 1: Variables included in neighborhood classification analysis

\begin{tabular}{|c|c|c|}
\hline Variable description & Variable name & Source \\
\hline Number of jobs within a 45 -minute drive & Job access & (1) \\
\hline Share of total CBSA employment ${ }^{\mathrm{a}}$ & Job share & (2) \\
\hline Share of total activity that is employment ${ }^{b}$ & Percent jobs & (2) \\
\hline Share of total activity that is office employment ${ }^{b}$ & Percent office & (2) \\
\hline Share of total activity that is retail employment ${ }^{\mathrm{b}}$ & Percent retail & (2) \\
\hline Jobs-housing balance $^{\mathrm{c}}$ & Job-housing balance & (2) \\
\hline Housing density ${ }^{\mathrm{d}}$ & Housing density & (2) \\
\hline Employment density ${ }^{\mathrm{d}}$ & Job density & (2) \\
\hline Activity density ${ }^{\mathrm{b}, \mathrm{d}}$ & Activity density & (2) \\
\hline Total road network density ${ }^{\mathrm{d}}$ & Road density & (2) \\
\hline Pedestrian-oriented road network density ${ }^{\mathrm{d}}$ & Pedestrian density & (2) \\
\hline Car-oriented road network density ${ }^{\mathrm{d}}$ & Car network density & (2) \\
\hline Intersection density $^{\mathrm{d}}$ & Intersection density & (2) \\
\hline Transit service density index ${ }^{\mathrm{d}}$ & Transit supply index & (2) \\
\hline Share of homes that are single-family homes & Percent SFR & (3) \\
\hline Share of occupied homes that are rentals & Percent rented & (3) \\
\hline Share of occupied homes occupied for $<5$ years & Short-term homes & (3) \\
\hline Share of occupied homes occupied for $>20$ years & Long-term homes & (3) \\
\hline Share of homes less than ten years old & New homes & (3) \\
\hline Share of homes more than forty years old & Old homes & $(3)$ \\
\hline $\begin{array}{l}\text { Notes: } \\
\text { a. Calculated as the percentage of all jobs in the ce } \\
\text { that are located within the census tract. } \\
\text { b. As used here, "activity" is the number of homes } \\
\text { tract. } \\
\text { c. This value is computed as } 1-2 \mid \text { (Percent jobs - } \\
\text { value of } 1 \text { indicates that there are equal number } \\
\text { indicates that there are either no jobs or no hom } \\
\text { d. Variable was log-transformed prior to inclusion } \\
\text { Sources } \\
\text { 1. Taken directly from the EPA Smart Location } \\
\text { 2. Calculated from values given in the EPA Sm } \\
\text { Bell, 2014) } \\
\text { 3. U.S. Decennial Census (United States Censu }\end{array}$ & $\begin{array}{l}\text { re-based statistical are } \\
\text { plus the number of jot } \\
.5) \mid . \text { A jobs-housing be } \\
\text { of homes and jobs. A } \\
\text { es in the tract. } \\
\text { in the factor analysis }\end{array}$ & $\begin{array}{l}\text { CBSA) } \\
\text { in the } \\
\text { nce } \\
\text { lue of } 0 \\
1,2014 \text { ) } \\
\text { msey \& }\end{array}$ \\
\hline
\end{tabular}


We reduced the initial set of 20 variables listed in Table 1 to a set of five factors using the "psych package" for the statistical analysis software R (Revelle 2014). ${ }^{1}$ Following the factor analysis, we conducted a cluster analysis using the "fastcluster package" in R (Müllner 2013), including each of the five factor scores for most census tracts in the United States (some tracts were omitted due to missing data).

Just as the number of factors must be specified prior to factor analysis, the number of clusters must also be specified prior to cluster analysis. There are many available indices and rules that a researcher may use to determine the correct number of clusters. We computed index values for 14 different internal indices using the R package "clusterCrit" (Desgraupes 2014) and selected the number of clusters that the greatest number of criteria determined to be optimal.

Based on an initial factor analysis and subsequent cluster analysis, we identified 10 census tracts (out of more than 73,000 ) that had very low populations and factor scores that were clearly outliers. ${ }^{2}$ Since factor scores are computed to have a mean of zero and a standard deviation of one, these few outliers had a large effect on the factor scores for all observations. Therefore, we removed these 10 census tracts from the sample and reran the analysis without them. As noted above, we excluded other census tracks from the analysis due to missing data. Ultimately, our analysis includes a sample of 72,183 census tracts, which represents 99 percent of the 73,057 census tracts in the United States.

After defining a set of neighborhood types, we examined the relationship between neighborhood type and survey-day travel behavior reported by respondents to the most recent National Household Travel Survey (NHTS), conducted in 2009. The NHTS is commissioned periodically by the Federal Highway Administration (FHWA) and includes a detailed travel diary over a 24-hour period (FHWA 2011). Respondents record each trip they make, including the purpose of the trip as well as travel mode, duration, and distance.

The NHTS sample includes respondents from all 50 states and the confidential data link individual respondents to the census tract in which they live. These data, therefore, enable analysis of travel patterns in various geographic settings and the broad sampling ensures that the findings are more generalizable than similar studies conducted in a single metropolitan region or state.

We describe survey-day travel in terms of four variables. Two of these, person miles of travel (PMT) and number of survey-day trips, describe the amount of survey-day travel. The other two indicate whether a survey respondent made at least one survey-day trip by single-occupancy vehicle (SOV) and whether he or she made at least one trip by public transit. For each of these travel behavior variables, we first analyzed descriptive patterns by neighborhood type, and then estimated multivariate models. This was necessary because the personal characteristics of respondents vary considerably by residential location, and as a result descriptive results may misrepresent the independent relationship between neighborhood type and travel.

\footnotetext{
${ }^{1}$ Factor analysis requires an a priori specification of the desired number of factors. A variety of methods are available to determine the appropriate number of factors. Two of the most common are the scree test based on a visual inspection of a graphical representation of eigenvalues (Cattell 1966) and the eigenvalue-greater-than-one rule (Kaiser 1960). In spite of their widespread use, both methods have major weaknesses and are no longer recommended (Ledesman and Valero-Mora 2007). Rather than applying either of these rules, we tested solutions with five to eight factors and selected the number of factors within this range with the clearest interpretability and greatest consistency with existing literature on the built environment.

${ }^{2}$ The 10 tracts removed are: (1) the portion of the Tohono O'odom Nation Reservation in Maricopa County, Arizona; (2) the Farallon Islands, located off the coast of San Francisco, which are closed to the public and exclusively inhabited by wildlife researchers; (3) Channel Islands National Park, located off the coast of Santa Barbara; (4) Biscayne National Park, located off the coast of Miami; (5) the Loxahatchee Slough Natural Area, a 12,000-acre wetland nature preserve located in Palm Beach Gardens, Florida; (6) the unincorporated area of Polk County, Florida, to the northeast of Lake Hatchineha; (7) Island Beach State Park in Ocean County, New Jersey; (8) the Great Bay Boulevard Wildlife Management Area in Ocean County, New Jersey; (9) the portion of the Oil Springs Reservation (Seneca Nation) in Allegheny County, New York; and (10) the Government Canyon State Natural Area in San Antonio, Texas. The combined population of these 10 tracts was 151 people, based on the 2010 census.
} 
We used a Tobit (censored) regression model for PMT, censored at zero daily person miles. Since the number of survey-day trips is a count variable, we modeled it using a negative binomial regression. Finally, we used Tobit regression models with censoring at zero and 100 percent to model the percent of a person's daily trips made by single-occupancy vehicle and by public transit. We drew the control variables for each model from the existing travel behavior literature. These variables include an array of personal and household characteristics. To determine the extent to which neighborhood type may be associated with differences in travel behavior that are above and beyond the effects of one-dimensional characteristics of the built environment, we estimated three sets of regression models for each outcome variable. The first set (which we refer to as Model A) describes the built environment exclusively in terms of neighborhood type. To test for the synergistic effects of built-form characteristics on travel, we estimate a second set of models (Model B) that also includes as independent variables the factor scores that were used as inputs to the cluster analysis. A final set of models (Model C) includes the factor scores but not the neighborhood types.

Previous work by Blumenberg et al. (2012) suggests that travel behavior, and in particular person miles of travel, varies systematically by age category, with the travel behavior of young people (ages 15 to 26), adults (27 to 61), and seniors (ages 62 and older) all distinct from one another. So rather than use categories of age unrelated to travel behavior (such as 18 to 21, 30 to 39, or 65 and older), we used travel-based age categories developed by Blumenberg et al. (2012) and limited our analysis to the "adults" age category. This sample includes respondents living in 30,308 different census tracts, representing about 41 percent of all census tracts in the United States.

The NHTS data include weights for use in transforming the sample data to better represent the US population in cases where particular subpopulations may have been over- or under-sampled. We have applied these weights to compute all descriptive statistics presented in this analysis. As recommended by Solon, Haider, and Wooldridge (2015) and Winship and Radbill (1994), weights were not applied to the regression analysis, since the sampling weights are a function of the independent variables included in the models and the probability of selection does not vary with the independent variables.

Our analysis does not control for residential self-selection. However, through the classification of all neighborhoods in the United States, we determine the relative availability of each neighborhood type into which residents may select. If neighborhood types associated with distinctive travel behavior represent a relatively small proportion of all neighborhoods or are found in but a limited number of cities, this would support Levine, Inam, and Torng's (2005) contention that residential self-selection may be an important mechanism by which the built environment influences travel behavior when individuals have a greater variety of neighborhood types from which to select a residential location.

\section{$4 \quad$ Results}

The results of the factor analysis of neighborhood characteristics are shown in Table 2, including the resulting eigenvalues. As noted in footnote 1 in the data and methodology section, the number of factors was selected based on interpretability rather than on Cattell's (1966) eigenvalue scree test or Kaiser's (1960) eigenvalue greater-than-one rule. We determined the five-factor solution to be the most interpretable and consistent with existing literature on travel and the built environment; the five factors generally indicate the degrees to which a neighborhood is dense, diverse, transient, established, and accessible. 
Table 2: Factor analysis results

\begin{tabular}{|c|c|c|c|c|c|}
\hline & $\begin{array}{c}\text { Factor 1: } \\
\text { Dense }\end{array}$ & $\begin{array}{l}\text { Factor 2: } \\
\text { Diverse }\end{array}$ & $\begin{array}{l}\text { Factor 3: } \\
\text { Transient } \\
\end{array}$ & $\begin{array}{c}\text { Factor 4: } \\
\text { Established }\end{array}$ & $\begin{array}{r}\text { Factor 5: } \\
\text { Accessible }\end{array}$ \\
\hline Eigenvalues & 7.22 & 2.61 & 1.93 & 1.17 & 0.51 \\
\hline Variable $^{1}$ & \multicolumn{5}{|c|}{ Variable Factor Loadings $^{2}$} \\
\hline Intersection density & 0.99 & & & & \\
\hline Pedestrian density & 0.99 & & & & \\
\hline Road density & 0.99 & & & & \\
\hline Housing density & 0.88 & & & & 0.21 \\
\hline Activity density & 0.85 & & & & 0.24 \\
\hline Job density & 0.69 & 0.38 & & & 0.20 \\
\hline Transit supply index & 0.52 & & & & 0.23 \\
\hline Job access & 0.30 & & & & 0.42 \\
\hline Car network density & -0.29 & 0.21 & & & \\
\hline Percent jobs & & 0.98 & & & \\
\hline Job-housing balance & & 0.80 & & & \\
\hline Percent office & & 0.57 & & & \\
\hline Percent retail & & 0.48 & & & \\
\hline Job share & & 0.32 & & & \\
\hline Percent rented & & & 0.97 & & \\
\hline Percent SFR & & & -0.73 & & \\
\hline Short-term homes & & & 0.70 & -0.40 & \\
\hline Long-term homes & & & -0.38 & 0.67 & \\
\hline Old homes & & & 0.20 & 0.73 & \\
\hline New homes & & & & -0.74 & \\
\hline $\begin{array}{l}\text { Notes: } \\
\text { 1. Refer to Table } 1 \text { for } \\
\text { 2. Loadings with a ma }\end{array}$ & $\begin{array}{l}\text { escription } \\
\text { itude of } 1\end{array}$ & $\begin{array}{l}\text { feach var } \\
\text { than } 0.20\end{array}$ & not shown. & & \\
\hline
\end{tabular}

We used the standardized factor scores for each census tract to conduct the cluster analysis. We computed stopping criteria indices for solutions from five to 12 clusters. Table 3 shows the number of factors suggested by each of the internal indices that we computed. For more information on these indices, see Desgraupes (2013). Based on the indices listed in Table 3, we determined a seven-cluster solution to be most appropriate. ${ }^{3}$

\footnotetext{
${ }^{3}$ The greatest number of indices (four) suggests a five-cluster solution. However, since five is the minimum number of clusters for which indices were computed, this does not necessarily represent a consensus among those four indices as to the best solution, since they each might indicate any number of clusters between two and five. Likewise, two indices suggest a 12-cluster solution, which is the maximum number for which indices were tested and could indicate any number of clusters greater than 11. Of the remaining eight indices computed, three suggested a seven-cluster solution, three suggested an eight-cluster solution, one suggested an 11-cluster solution, and one did not indicate an optimal number of clusters. Since equal numbers of indices suggested a seven-cluster and an eight-cluster solution, the median number of clusters from Table 3 was used to "break the tie."
} 
Table 3: Internal indices to determine the number of clusters (Desgraupes 2014)

\begin{tabular}{lc}
\hline Internal clustering index & $\begin{array}{c}\text { Suggested number } \\
\text { of clusters }\end{array}$ \\
\hline Calinski-Harabasz & $<6$ \\
McClain-Rao & $<6$ \\
Ratkowsky-Lance & $<6$ \\
Wemmert-Gançarski & $<6$ \\
Ball-Hall & 7 \\
$|T /| W \mid$ & 7 \\
$k^{2}|W|$ & 7 \\
Dunn & 8 \\
PBM & 8 \\
Ray-Turi & 8 \\
Davies-Bouldin & 11 \\
Banfeld-Raftery & $>11$ \\
Xie-Beni & Undefined \\
Point biserial & \\
\hline
\end{tabular}

\subsection{Neighborhood types}

To help readers conceptualize the various neighborhood types, we labeled each of them based on their average built-environment characteristics and on observations of the clusters' spatial arrangement within parts of cities with which members of the research team were familiar (Anchorage, Honolulu, Long Beach, Los Angeles, New York City, Pittsburgh, Provo, Salt Lake City, San Francisco, and Santa Clarita). This exercise suggested consistency in neighborhood types across areas, which allowed us to attach names that broadly (if incompletely) characterize seven neighborhood types: Rural, New Development, Patchwork (mostly suburban), Established Suburbs, Urban Residential, Old Urban, and Mixed-Use (mostly urban). We refer to the New Development, Patchwork, and Established Suburbs neighborhood types collectively as "suburban," and Urban Residential, Old Urban, and Mixed-Use neighborhoods collectively as "urban."

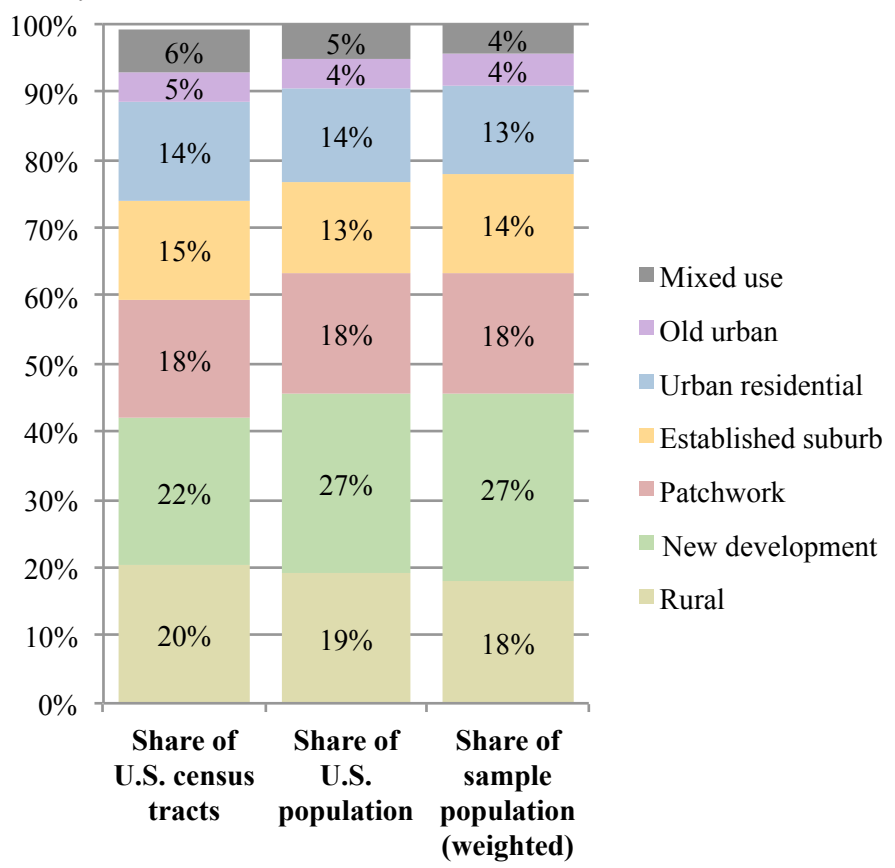

Figure 1: Prevalence of neighborhood types 
Figure 1 illustrates the relative prevalence of neighborhood types in terms of shares of all census tracts in the United States, shares of the total US population, and shares of the sample population. The shares of the sample population for all neighborhood types are within one percentage point of the shares of the total US population. New Development neighborhoods are the most prevalent, representing 22 percent of all census tracts, and are home to 27 percent of the US population. Old Urban neighborhoods are the least prevalent, representing just 5 percent of all census tracts and 4 percent of the total population. Most of the borough of Manhattan in New York City is characterized as Old Urban. In fact, the New York City metropolitan area is home to 50 percent of all Old Urban neighborhoods in the United States. Together, the three largest US metropolitan areas (New York, Los Angeles, and Chicago) account for over 80 percent of all Old Urban neighborhoods.

Mixed-Use neighborhoods are almost as rare as Old Urban neighborhoods, but are much more evenly distributed among metropolitan areas. Fifty-eight percent of all metropolitan and micropolitan statistical areas have at least one Mixed-Use neighborhood. They represent 6 percent of all census tracts and are home to 5 percent of the population. Examples of Mixed-Use neighborhoods are the financial districts of San Francisco and New York City, downtown Los Angeles, and inside the Chicago Loop.

While many cities have a cluster of Mixed-Use neighborhoods at the city center, this neighborhood type is not confined to downtowns. There are also Mixed-Use neighborhoods in commercial centers located closer to the edges of many cities. Likewise, there are several Rural neighborhoods surrounded on all sides by Established Suburbs or even adjacent to one or more of the three urban neighborhood types (Urban Residential, Old Urban, and Mixed-Use). Nevertheless, in many cities, the neighborhood types are arranged in ways that evoke the familiar concentric ring patterns described in classical theories of urban geography described by Burgess (1925) and Hoyt (1939). Moving from the center of each city to the outskirts, there is a distinct, if varied, progression from Mixed-Use to Old Urban to Urban Residential to Established Suburb to Patchwork to New Development to Rural. Figures 2, 3, 4, and 5 illustrate these patterns in Chicago, Los Angeles, New York City, and for the contiguous 48 states of the United States, respectively.

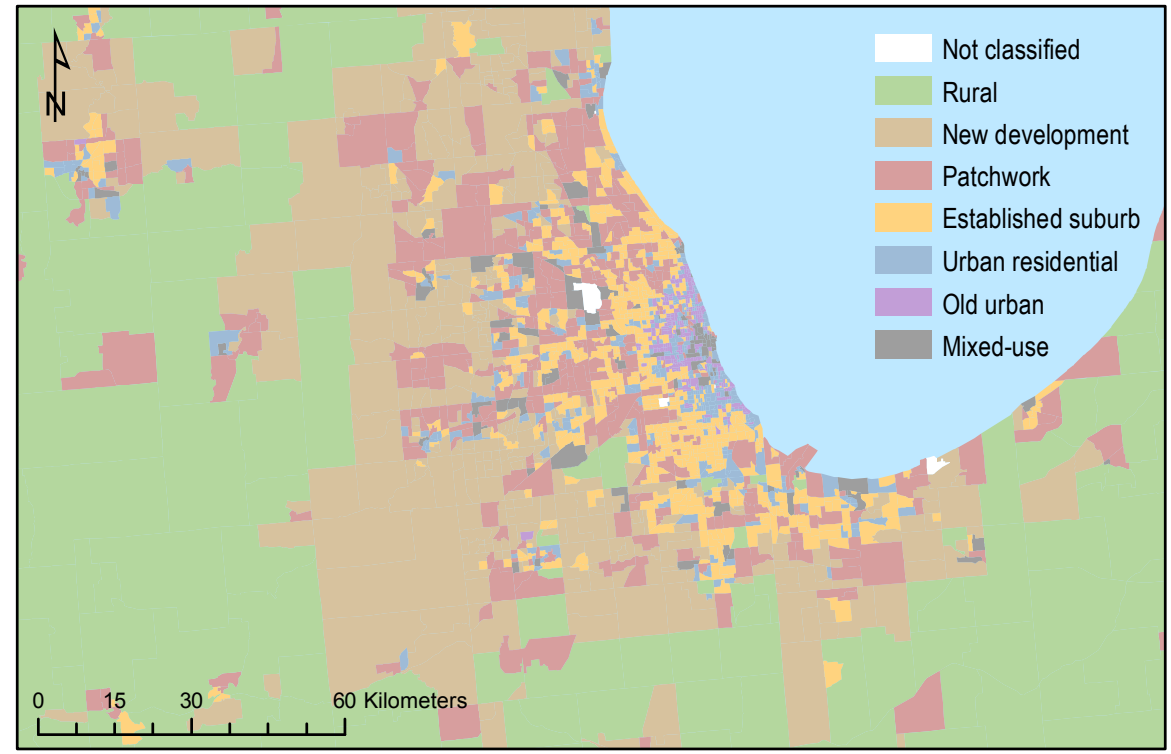

Figure 2: Spatial arrangement of neighborhood types in Chicago 


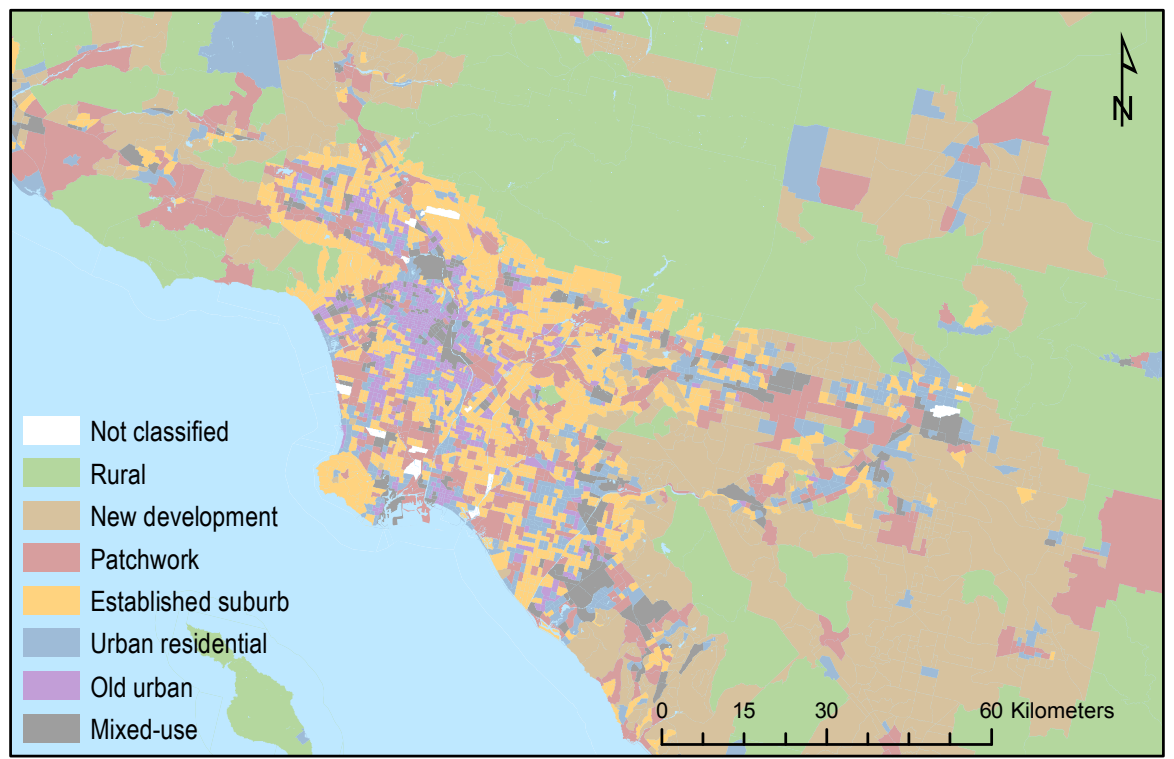

Figure 3: Spatial arrangement of neighborhood types in Los Angeles

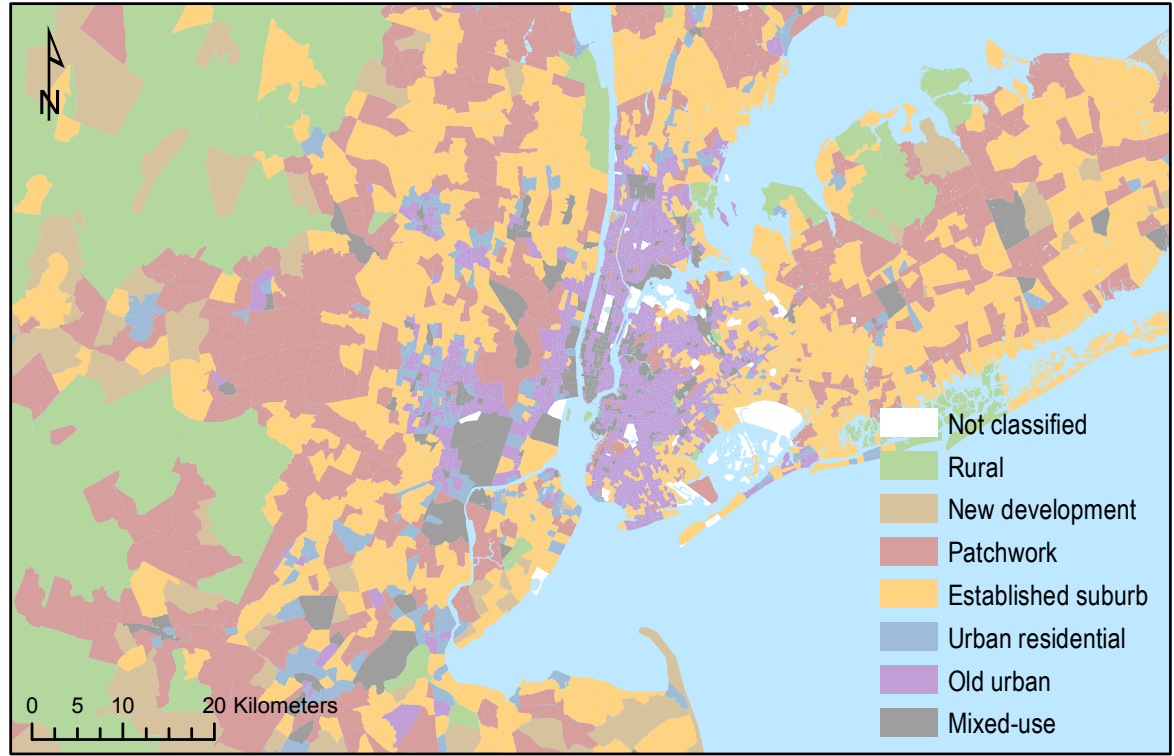

Figure 4: Spatial arrangement of neighborhood types in New York City 


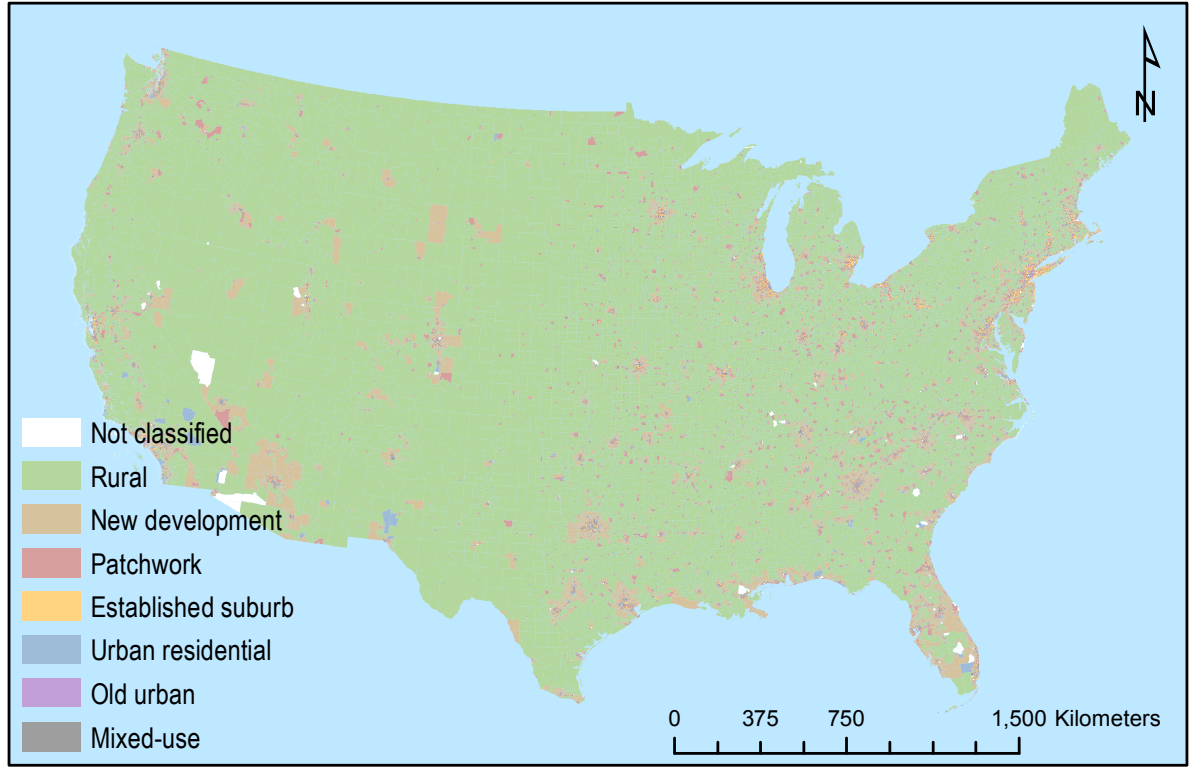

Figure 5: Spatial arrangement of neighborhood types in the contiguous 48 states of the United States

Since a large proportion of Old Urban neighborhoods are concentrated in New York City, the question arises as to whether differences between Old Urban neighborhoods and other neighborhood types may simply be attributed to their being in New York City. In other words, is travel in Old Urban neighborhoods distinctive because most of them are located in New York City, or is travel in New York City distinctive because it has so many Old Urban neighborhoods? We shed light on this question by presenting descriptive statistics of Old Urban neighborhoods both including and excluding the Old Urban neighborhoods that are in New York City.

Table 4: Average built environment characteristics by neighborhood type

\begin{tabular}{lcccccc}
\hline & $\begin{array}{c}\text { Homes } \\
\text { per } \\
\text { acre }\end{array}$ & $\begin{array}{c}\text { Jobs- } \\
\text { housing } \\
\text { balance }\end{array}$ & $\begin{array}{c}\text { Percent } \\
\text { rental } \\
\text { homes }\end{array}$ & $\begin{array}{c}\text { Percent of } \\
\text { homes }>40 \\
\text { years old }\end{array}$ & $\begin{array}{c}\text { Jobs within } \\
\text { a 45-minute } \\
\text { drive } \\
\text { (thousands) }\end{array}$ & $\begin{array}{c}\text { Transit } \\
\text { supply } \\
\text { index }\end{array}$ \\
\hline All Neighborhoods & 3.5 & 0.4 & $34 \%$ & $46 \%$ & 118 & 0.5 \\
\hline Rural & 0.1 & 0.3 & $19 \%$ & $42 \%$ & 14 & 0.0 \\
\hline Suburban types & & & & & & \\
\hline New Development & 1.4 & 0.2 & $19 \%$ & $17 \%$ & 68 & 0.0 \\
Patchwork & 1.7 & 0.7 & $35 \%$ & $46 \%$ & 94 & 0.1 \\
Established Suburbs & 4.1 & 0.3 & $25 \%$ & $74 \%$ & 186 & 0.6 \\
\hline Urban types & & & & & & \\
\hline Urban Residential & 5.9 & 0.3 & $58 \%$ & $56 \%$ & 147 & 0.8 \\
\hline Old Urban & 27.5 & 0.3 & $76 \%$ & $74 \%$ & 533 & 4.2 \\
(excluding NYC) & 17.4 & 0.3 & $76 \%$ & $69 \%$ & 438 & 5.2 \\
\hline Mixed-use & 5.2 & 0.7 & $65 \%$ & $49 \%$ & 181 & 1.1 \\
\hline
\end{tabular}




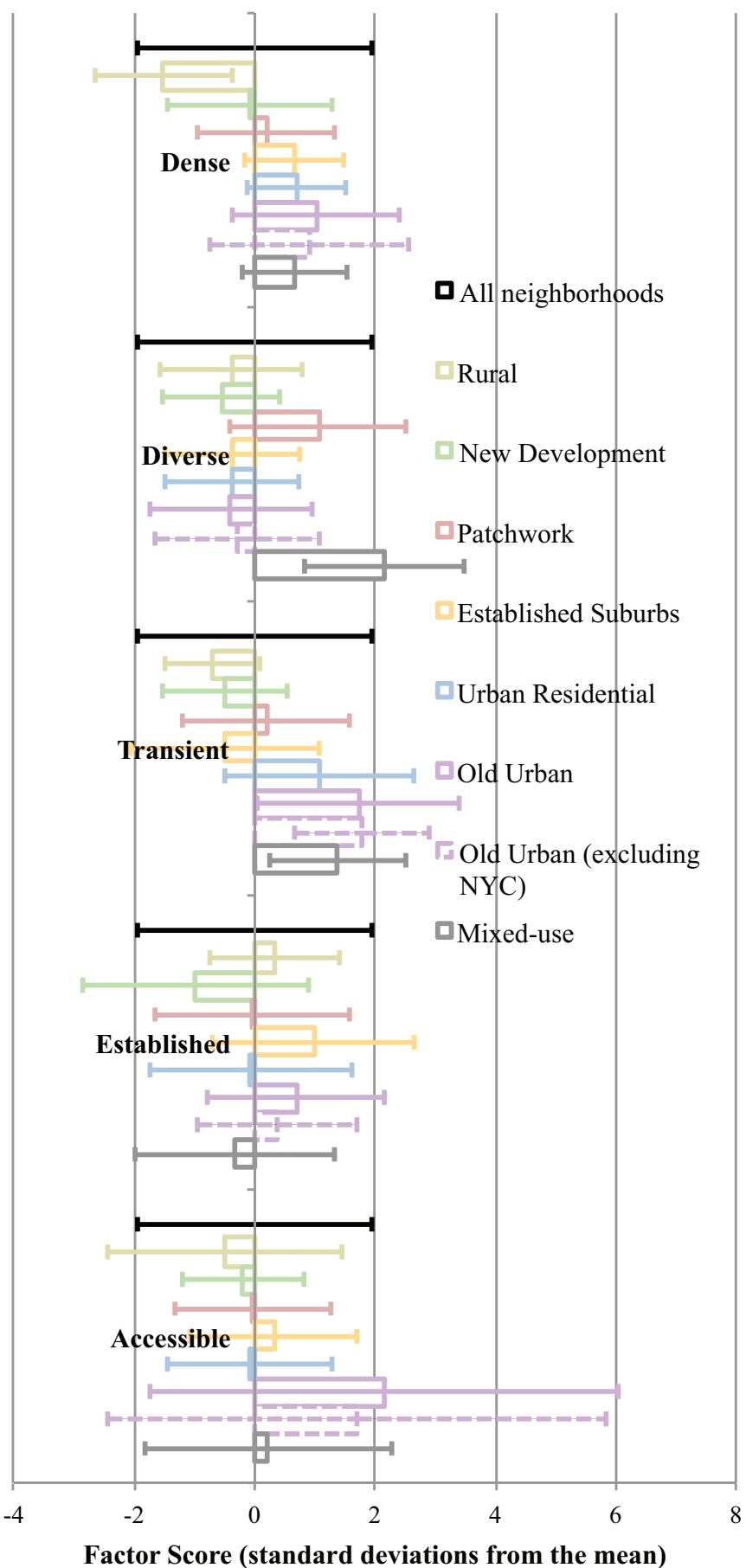

Figure 6: Average factor scores by neighborhood type, with error bars to indicate 95 percent confidence intervals

Table 4 shows how the seven neighborhood types vary in terms of each of the selected built-environment characteristics. Figure 6 shows how the factor scores vary among neighborhood types. The Patchwork and Mixed-Use neighborhood types, for example, have similar high scores on the jobs-housing balance index; however, the housing density is much higher in Mixed-Use neighborhoods than in Patchwork neighborhoods. Likewise, the age of the housing in Old Urban neighborhoods is similar to 
that in Established Suburbs, but the housing density in Old Urban neighborhoods is nearly seven times that of Established Suburbs. While Old Urban neighborhoods outside of New York City are, on average, 37 percent less dense and have nearly 18 percent fewer jobs within a 45-minute drive, they are still three times denser than any other neighborhood type and near 2.4 times as many jobs on average. The other descriptors of Old Urban neighborhoods shown in Table 4 are comparable with and without New York City included, and in fact the average level of transit supply in non-New York Old Urban neighborhoods is higher than when New York City is included.

\subsection{Travel behavior outcomes}

Figure 7 shows the mean and median survey-day PMT by residents of each neighborhood type. Residents of Rural neighborhoods had the highest median level of survey-day PMT, and residents of Old Urban neighborhoods had the lowest. Among the three suburban neighborhood types, New Development neighborhoods have the highest PMT, and are in fact more similar to Rural neighborhoods in this respect than to the other suburban neighborhood types. PMT in the urban neighborhood types is only slightly lower than in the other types of suburban neighborhood, with the exception of Old Urban neighborhoods, where PMT is much lower than in other urban neighborhood types, and half of the lowest level that is observed in other neighborhood types.

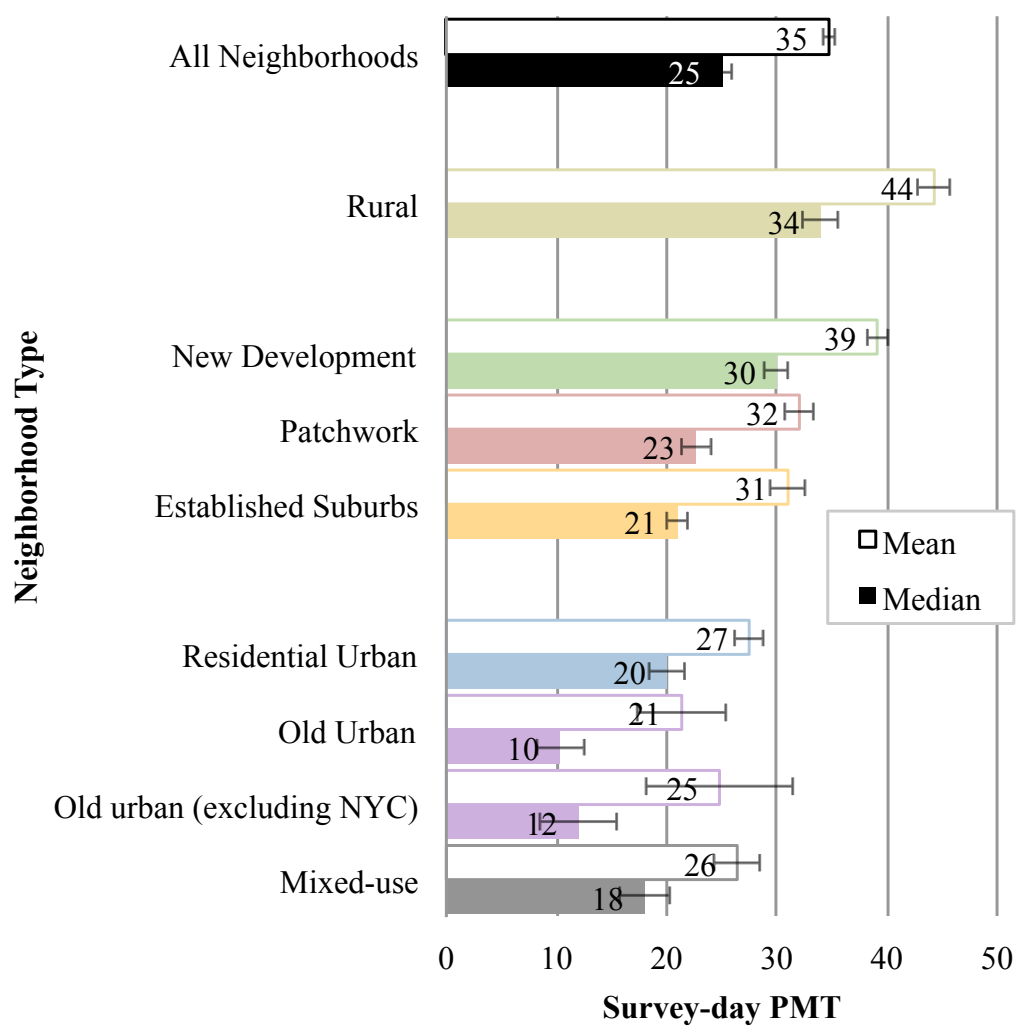

Figure 7: Mean and median survey-day PMT by neighborhood type, with error bars indicating 95 percent confidence intervals 
Figure 8 shows that the median number of survey-day trips is consistent across neighborhood types, with any differences staying within the 95 percent confidence intervals. This finding suggests that the variation in PMT (shown in Figure 7) is a result of variation in trip length rather than in trip making. In fact, although adults in Rural neighborhoods had higher survey-day PMT than adults in other neighborhood types, the median number of survey-day trips for adults in Rural neighborhoods is actually lower than in any other neighborhood type other than Old Urban, suggesting that high levels of mobility in rural neighborhoods do not necessarily result in high levels of access to destinations.

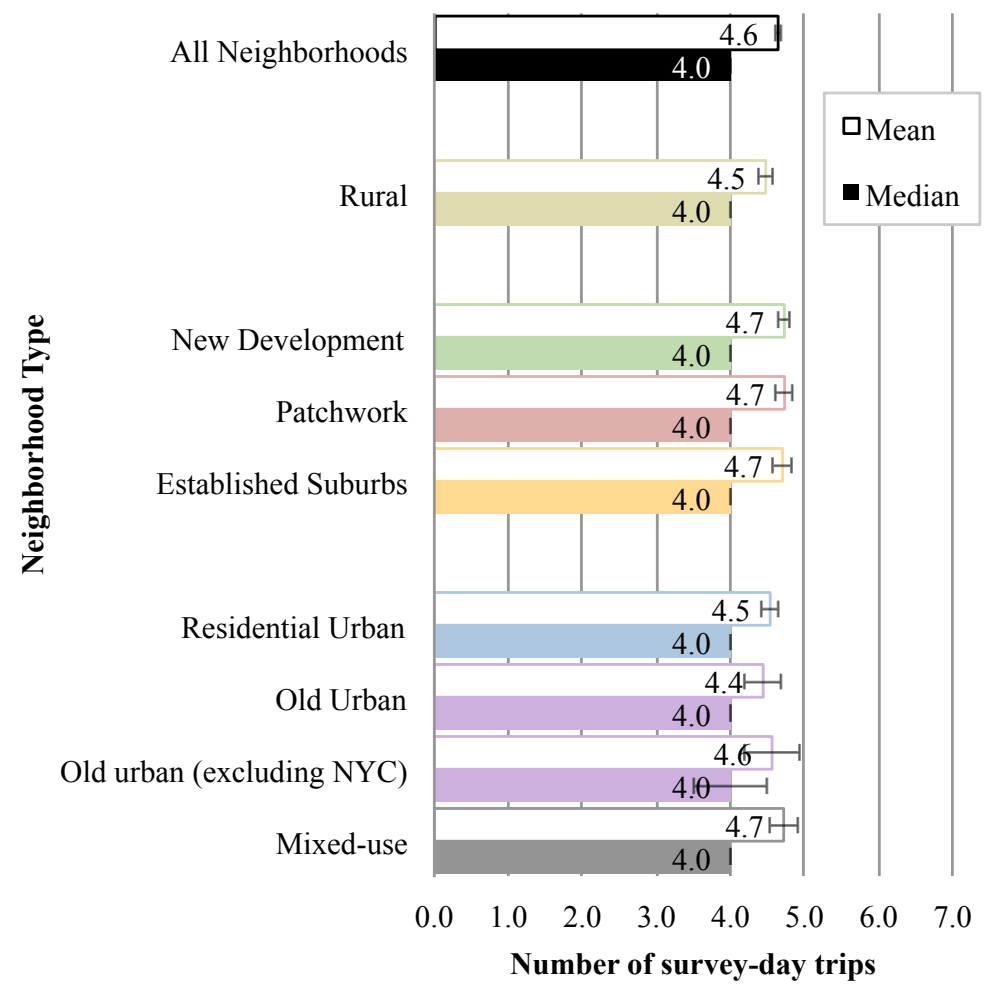

Figure 8: Mean and median number of survey-day trips by neighborhood type, with error bars indicating 95 percent confidence intervals

As Figure 9 shows, mode shares were likewise consistent across neighborhood types, with the striking exception of Old Urban neighborhoods, for which the share of trips by every mode was different from any other neighborhood at a 95 percent confidence level. The only neighborhood type in which SOV trips represented less than 45 percent of all survey-day trips by adults is Old Urban. 


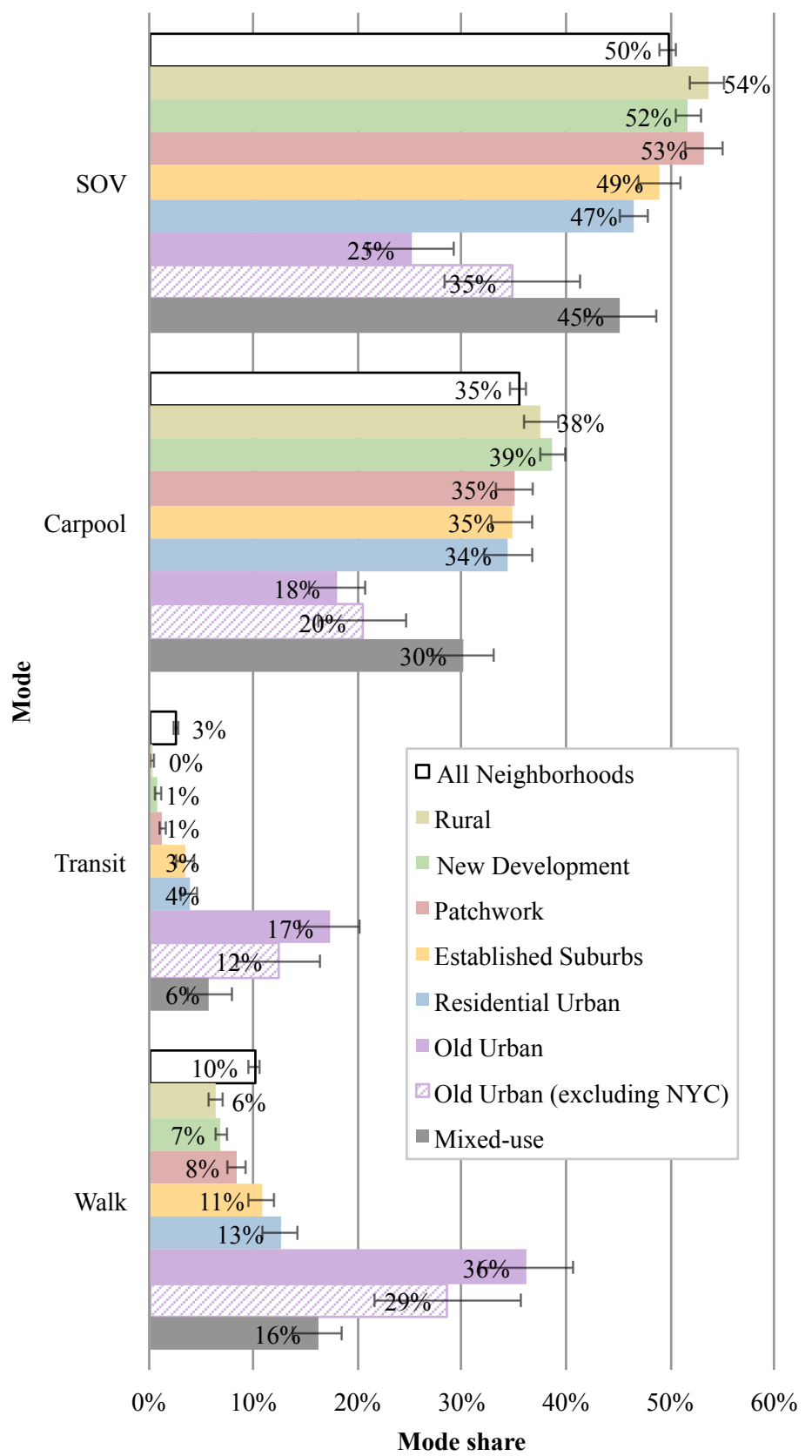

Figure 9: Percentage of survey-day trips by each mode, by neighborhood type, with error bars indicating 95 percent confidence intervals

Figures 7, 8, and 9 show remarkable differences in travel behavior between Old Urban neighborhoods and all other neighborhood types, even when New York City Old Urban neighborhoods are excluded from the analysis. This suggests that the distinctive travel behavior in Old Urban neighborhoods is not simply a "New York effect," but rather the distinctive travel patterns in New York may be explained, at least in part, by its abundance of Old Urban neighborhoods. 


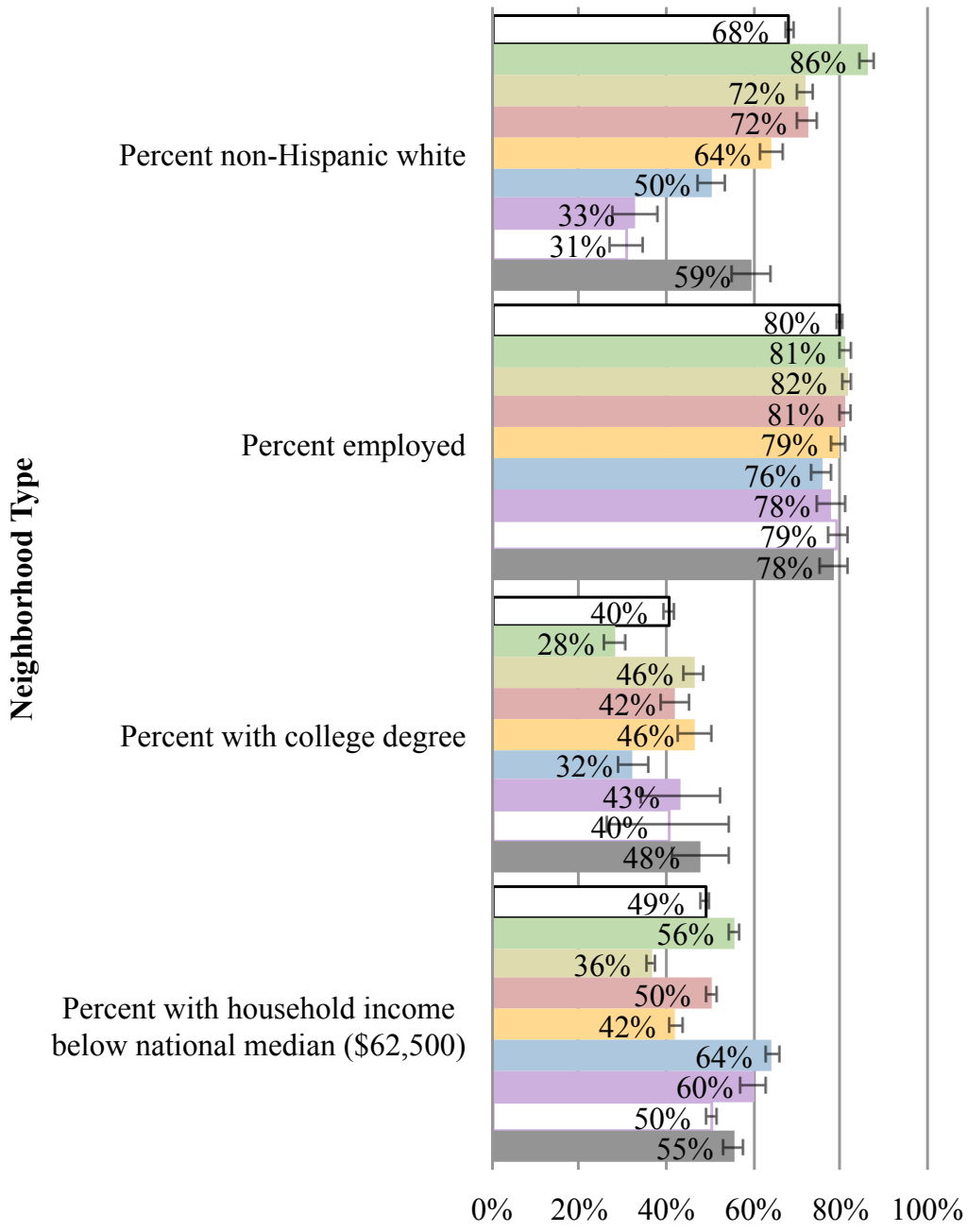

Percentage based on weighted NHTS data

\begin{tabular}{|ll|}
\hline$\square$ All Neighborhoods & Rural \\
$\square$ New Development & $\square$ Patchwork \\
Established Suburbs & $\square$ Urban Residential \\
$\square$ Old Urban & $\square$ (Old Urban excluding NYC) \\
$\square$ Mixed-use & \\
\hline
\end{tabular}

Figure 10: Demographic characteristics of residents by neighborhood type, with error bars indicating 95 percent confidence intervals

As shown in Figure 10, although neighborhood types were not defined by the socioeconomic or demographic characteristics of their residents, they do differ substantially by characteristics such as average income, racial composition, and average education levels. Since such characteristics are known to influence travel behavior, we ran several regression models to determine the independent effect of neighborhood type on PMT, number of trips, and mode choice, controlling for these individual and household characteristics. 
Table 5: Results of Tobit regression models for PMT (models censored at zero PMT)

\begin{tabular}{|c|c|c|c|c|c|c|}
\hline \multirow{3}{*}{$\begin{array}{l}\mathbf{R}^{2} \\
\text { Variable }\end{array}$} & \multicolumn{2}{|c|}{ Model A } & \multicolumn{2}{|c|}{ Model B } & \multicolumn{2}{|c|}{ Model C } \\
\hline & \multicolumn{2}{|c|}{0.0509} & \multicolumn{2}{|c|}{0.0638} & \multicolumn{2}{|c|}{0.0636} \\
\hline & Coefficient & p-value & Coefficient & p-value & Coefficient & p-value \\
\hline \multicolumn{7}{|c|}{ Personal Characteristics } \\
\hline Age & 0.01 & 0.322 & 0.01 & 0.464 & 0.01 & 0.467 \\
\hline \multicolumn{7}{|l|}{ Sex (Base: Male) } \\
\hline Female & -2.99 & $<0.001$ & -2.99 & $<0.001$ & -2.99 & $<0.001$ \\
\hline \multicolumn{7}{|c|}{ Racelethnicity (Base: Non-Hispanic White) } \\
\hline Non-Hispanic Black & 3.84 & $<0.001$ & 4.33 & $<0.001$ & 4.29 & $<0.001$ \\
\hline Non-Hispanic Asian & -1.16 & 0.068 & -0.13 & 0.842 & -0.13 & 0.843 \\
\hline Hispanic & 1.31 & 0.001 & 2.32 & $<0.001$ & 2.29 & $<0.001$ \\
\hline Other & 1.32 & 0.037 & 1.59 & 0.012 & 1.57 & 0.013 \\
\hline \multicolumn{7}{|c|}{ Employment (Base: Employed) } \\
\hline Not employed & -11.71 & $<0.001$ & -11.71 & $<0.001$ & -11.71 & $<0.001$ \\
\hline \multicolumn{7}{|c|}{ Internet use (Base: Daily) } \\
\hline Less than daily & -2.67 & $<0.001$ & -2.74 & $<0.001$ & -2.74 & $<0.001$ \\
\hline \multicolumn{7}{|l|}{ Household characteristics } \\
\hline \multicolumn{7}{|c|}{ Education (Base: Less than high school) } \\
\hline High school & 4.47 & $<0.001$ & 4.47 & $<0.001$ & 4.48 & $<0.001$ \\
\hline Some college & 6.22 & $<0.001$ & 6.39 & $<0.001$ & 6.39 & $<0.001$ \\
\hline Four-year degree & 5.84 & $<0.001$ & 6.16 & $<0.001$ & 6.17 & $<0.001$ \\
\hline Graduate degree & 4.62 & $<0.001$ & 5.07 & $<0.001$ & 5.07 & $<0.001$ \\
\hline Income $(\$ 10,000 \mathrm{~s})$ & 0.54 & $<0.001$ & 0.54 & $<0.001$ & 0.53 & $<0.001$ \\
\hline Number of $\mathrm{HH}$ adults & -0.31 & 0.034 & -0.35 & 0.016 & -0.35 & 0.016 \\
\hline Number of $\mathrm{HH}$ children & 1.60 & $<0.001$ & 1.53 & $<0.001$ & 1.53 & $<0.001$ \\
\hline \multicolumn{7}{|c|}{ Neighborhood characteristics } \\
\hline \multicolumn{7}{|c|}{ Factor scores } \\
\hline Dense & - & - & -4.22 & $<0.001$ & -4.52 & $<0.001$ \\
\hline Diverse & - & - & -1.08 & $<0.001$ & -0.95 & $<0.001$ \\
\hline Transient & - & - & -1.55 & $<0.001$ & -1.70 & $<0.001$ \\
\hline Established & - & - & -0.64 & $<0.001$ & -0.69 & $<0.001$ \\
\hline Accessible & - & - & -0.51 & 0.002 & -0.68 & $<0.001$ \\
\hline \multicolumn{7}{|c|}{ Neighborhood type (Base: Rural) } \\
\hline New development & -5.25 & $<0.001$ & -0.62 & 0.137 & - & - \\
\hline Patchwork & -9.30 & $<0.001$ & -0.56 & 0.274 & - & - \\
\hline Established suburb & -10.30 & $<0.001$ & -1.26 & 0.017 & - & - \\
\hline Urban residential & -11.72 & $<0.001$ & -1.18 & 0.048 & - & - \\
\hline Old urban & -18.24 & $<0.001$ & -3.10 & 0.007 & - & - \\
\hline Mixed-use & -13.82 & $<0.001$ & -0.58 & 0.497 & - & - \\
\hline
\end{tabular}

Table 5 summarizes the estimated effects of neighborhood type on survey-day PMT. ${ }^{4}$ The columns for Model A show that even when controlling for individual and household characteristics, the effect of neighborhood type on PMT is statistically significant. Holding individual and household characteristics constant, Rural respondents still had the highest PMT on the survey day (as is also the case when we do not control for personal and household characteristics). The reduction in survey-day PMT (relative to Rural neighborhoods) is the smallest for New Development neighborhoods (which are often found on the metropolitan fringe) and the largest for Old Urban neighborhoods. When we also control for the neighborhoods' factor scores as one-dimensional and independent measures of density, diversity, transience, stability, and accessibility, the additional effects of three neighborhood types-Established Suburb, Urban Residential, and Old Urban — remain statistically significant, indicating that these three neighborhood types are associated with differences in PMT above and beyond what would be predicted

\footnotetext{
${ }^{4}$ When the Old Urban neighborhoods in New York City are excluded from these models, coefficient estimates have the same directions and significance levels in all three models, with the exception of the Old Urban neighborhood coefficient in Model A, which is no longer significant and changes direction, and the New Development neighborhood coefficient in Model A, which becomes significant.
} 
based on individual built-environment characteristics. When we include individual factor scores in the model without including neighborhood type (Model C), the effects of the factor scores are of a similar magnitude to those in Model B. Of the three models, Model B best fits the data (as indicated by the R-squared statistic), although all three models explain only 5 to 7 percent of the variation in individual survey-day PMT, which is generally typical of models that seek to explain individual travel choices using socioeconomic and built-environment characteristics.

Table 6: Results of negative-binomial regression models for number of survey-day trips

\begin{tabular}{|c|c|c|c|c|c|c|}
\hline \multirow{3}{*}{\begin{tabular}{|l|} 
AIC* \\
Variable
\end{tabular}} & \multirow{2}{*}{\multicolumn{2}{|c|}{\begin{tabular}{|c|} 
Model A \\
529,301
\end{tabular}}} & \multicolumn{2}{|c|}{ Model B } & \multicolumn{2}{|c|}{ Model C } \\
\hline & & & \multicolumn{2}{|c|}{529,110} & \multicolumn{2}{|c|}{529,127} \\
\hline & Coefficient & p-value & Coefficient & p-value & Coefficient & p-value \\
\hline \multicolumn{7}{|c|}{ Personal Characteristics } \\
\hline Age & $<0.01$ & $<0.001$ & $<0.01$ & $<0.001$ & $<0.01$ & $<0.001$ \\
\hline \multicolumn{7}{|l|}{ Sex (Base: Male) } \\
\hline Female & 0.08 & $<0.001$ & 0.08 & $<0.001$ & 0.08 & $<0.001$ \\
\hline \multicolumn{7}{|c|}{ Racelethnicity (Base: Non-Hispanic White) } \\
\hline Non-Hispanic Black & -0.01 & 0.374 & -0.01 & 0.240 & -0.01 & 0.245 \\
\hline Non-Hispanic Asian & -0.12 & $<0.001$ & -0.12 & $<0.001$ & -0.12 & $<0.001$ \\
\hline Hispanic & -0.01 & 0.156 & -0.02 & 0.044 & -0.02 & 0.036 \\
\hline Other & -0.02 & 0.077 & -0.02 & 0.072 & -0.02 & 0.066 \\
\hline \multicolumn{7}{|c|}{ Employment (Base: Employed) } \\
\hline Not employed & -0.11 & $<0.001$ & -0.11 & $<0.001$ & -0.11 & $<0.001$ \\
\hline \multicolumn{7}{|l|}{ Internet use (Base: Daily) } \\
\hline Less than daily & -0.08 & $<0.001$ & -0.08 & $<0.001$ & -0.08 & $<0.001$ \\
\hline \multicolumn{7}{|c|}{ Household characteristics } \\
\hline \multicolumn{7}{|c|}{ Education (Base: Less than high school) } \\
\hline High school & 0.12 & $<0.001$ & 0.12 & $<0.001$ & 0.12 & $<0.001$ \\
\hline Some college & 0.20 & $<0.001$ & 0.20 & $<0.001$ & 0.20 & $<0.001$ \\
\hline Four-year degree & 0.25 & $<0.001$ & 0.25 & $<0.001$ & 0.25 & $<0.001$ \\
\hline Graduate degree & 0.27 & $<0.001$ & 0.27 & $<0.001$ & 0.27 & $<0.001$ \\
\hline Income $(\$ 10,000 \mathrm{~s})$ & 0.01 & $<0.001$ & 0.01 & $<0.001$ & 0.01 & $<0.001$ \\
\hline Number of $\mathrm{HH}$ adults & -0.04 & $<0.001$ & -0.04 & $<0.001$ & -0.04 & $<0.001$ \\
\hline Number of HH children & 0.08 & $<0.001$ & 0.08 & $<0.001$ & 0.08 & $<0.001$ \\
\hline \multicolumn{7}{|c|}{ Neighborhood characteristics } \\
\hline \multicolumn{7}{|c|}{ Factor scores } \\
\hline Dense & - & - & 0.03 & $<0.001$ & 0.04 & $<0.001$ \\
\hline Diverse & - & - & 0.02 & $<0.001$ & 0.01 & $<0.001$ \\
\hline Transient & - & - & 0.01 & 0.004 & $<0.01$ & 0.729 \\
\hline Established & - & - & 0.03 & $<0.001$ & 0.02 & $<0.001$ \\
\hline Accessible & - & - & $>-0.01$ & 0.882 & -0.01 & 0.66 \\
\hline \multicolumn{7}{|c|}{ Neighborhood type (Base: Rural) } \\
\hline New development & 0.03 & $<0.001$ & 0.03 & 0.002 & - & - \\
\hline Patchwork & 0.08 & $<0.001$ & 0.01 & 0.460 & - & - \\
\hline Established suburb & 0.01 & $<0.001$ & 0.01 & 0.324 & - & - \\
\hline Urban residential & 0.08 & $<0.001$ & 0.01 & 0.600 & - & - \\
\hline Old urban & 0.03 & 0.060 & -0.08 & 0.001 & - & - \\
\hline Mixed-use & 0.07 & $<0.001$ & -0.04 & 0.019 & - & - \\
\hline \multicolumn{7}{|c|}{$\begin{array}{l}\text { Statistically significant results (at a 95-percent confidence level) in black; non-significant } \\
\text { results in grey. } \\
\text { *The Akaike Information Criterion (AIC) indicates goodness of fit, where a lower AIC } \\
\text { value indicates a better fit to the data. }\end{array}$} \\
\hline
\end{tabular}

Table 6 summarizes the estimated effects of neighborhood type on the number of survey-day trips. ${ }^{5}$ Controlling for individual and household characteristics (Model A), respondents in all non-rural neighborhoods except Old Urban neighborhoods made more trips than those in Rural neighborhoods, despite traveling far fewer miles on average. Surprisingly, despite the much higher destination accessibility

\footnotetext{
${ }^{5}$ When the Old Urban neighborhoods in New York City are excluded from these models, coefficient estimates have the same directions and significance levels in all three models, with the following exceptions: The Old Urban and Mixed-Use neighborhood coefficients in Model A are no longer significant; the Old Urban neighborhood coefficient in Model B becomes significant; and the coefficients for the transience and accessibility factors in Model C become significant.
} 
in Old Urban neighborhoods relative to Rural neighborhoods (see Table 4), the number of daily trips made by Old Urban residents is no different than the number of daily trips made by Rural residents. In fact, when we control for built-environment characteristics, such as density and diversity in Model B, we find that residents of the Old Urban and Mixed-Use neighborhoods actually make fewer trips, on average, than their more rural counterparts. When we include individual factor score in the model without including neighborhood type (Model C), the effects of the factor scores are of a similar magnitude to those in Model B. Of the three models, Model B best fits the data, as indicated by the Akaike Information Criterion (AIC).

Table 7: Results of Tobit regression models for share of survey-day trips by SOV, censored at zero and 100 percent

\begin{tabular}{|c|c|c|c|c|c|c|}
\hline & Mode & $\mathbf{A}$ & Mode & & Mode & \\
\hline $\mathbf{R}^{2}$ & 0.089 & & 0.09 & & 0.08 & \\
\hline Variable $\quad \mathrm{C}$ & Coefficient & p-value & Coefficient & p-value & Coefficient & p-value \\
\hline Personal Characteristics & & & & & & \\
\hline Age & 0.01 & $<0.001$ & 0.01 & $<0.001$ & 0.01 & $<0.001$ \\
\hline Sex (Base: Male) & & & & & & \\
\hline Female & -0.14 & $<0.001$ & -0.14 & $<0.001$ & -0.14 & $<0.001$ \\
\hline Racelethnicity (Base: No & on-Hispanic & White) & & & & \\
\hline Non-Hispanic Black & $>-0.01$ & 0.895 & 0.01 & 0.542 & 0.01 & 0.563 \\
\hline Non-Hispanic Asian & 0.01 & 0.600 & -0.01 & 0.751 & 0.01 & 0.696 \\
\hline Hispanic & -0.08 & $<0.001$ & -0.07 & $<0.001$ & -0.07 & $<0.001$ \\
\hline Other & -0.03 & 0.148 & -0.02 & 0.288 & -0.02 & 0.240 \\
\hline Employment (Base: Emp & ployed) & & & & & \\
\hline Not employed & -0.51 & $<0.001$ & -0.51 & $<0.001$ & -0.51 & $<0.001$ \\
\hline Internet use (Base: Daily) & & & & & & \\
\hline Less than daily & -0.01 & 0.279 & -0.01 & 0.290 & -0.01 & 0.229 \\
\hline Household characteristic & & & & & & \\
\hline Education (Base: Less th & han high sch & hool) & & & & \\
\hline High school & 0.25 & $<0.001$ & 0.24 & $<0.001$ & 0.24 & $<0.001$ \\
\hline Some college & 0.26 & $<0.001$ & 0.26 & $<0.001$ & 0.26 & $<0.001$ \\
\hline Four-year degree & 0.20 & $<0.001$ & 0.20 & $<0.001$ & 0.20 & $<0.001$ \\
\hline Graduate degree & 0.14 & $<0.001$ & 0.15 & $<0.001$ & 0.15 & $<0.001$ \\
\hline Income $(\$ 10,000 s)$ & $<0.01$ & 0.103 & $<0.01$ & 0.228 & $<0.01$ & 0.199 \\
\hline Number of $\mathrm{HH}$ adults & -0.07 & $<0.001$ & -0.07 & $<0.001$ & -0.07 & $<0.001$ \\
\hline Number of HH children & -0.13 & $<0.001$ & -0.13 & $<0.001$ & -0.13 & $<0.001$ \\
\hline Neighborhood character & eristics & & & & & \\
\hline Factor scores & & & & & & \\
\hline Dense & - & - & -0.01 & 0.010 & -0.01 & 0.041 \\
\hline Diverse & - & - & 0.01 & 0.287 & 0.02 & $<0.001$ \\
\hline Transient & - & - & -0.05 & $<0.001$ & -0.07 & $<0.001$ \\
\hline Established & - & - & -0.01 & 0.006 & -0.01 & $<0.001$ \\
\hline Accessible & - & - & -0.04 & $<0.001$ & -0.07 & $<0.001$ \\
\hline Neighborhood type (Base & se: Rural) & & & & & \\
\hline New development & -0.01 & 0.216 & $<0.01$ & 0.781 & - & - \\
\hline Patchwork & -0.02 & 0.116 & 0.04 & 0.015 & - & - \\
\hline Established suburb & -0.04 & 0.001 & 0.02 & 0.263 & - & - \\
\hline Urban residential & -0.09 & $<0.001$ & 0.03 & 0.015 & - & - \\
\hline Old urban & -0.72 & $<0.001$ & -0.45 & $<0.001$ & - & - \\
\hline Mixed-use & -0.13 & $<0.001$ & -0.02 & 0.531 & - & - \\
\hline
\end{tabular}

Table 7 summarizes the estimated effects of neighborhood type on the percentage of survey-day trips made by SOV. ${ }^{6}$ When we control for individual and household characteristics, the share of surveyday trips by SOV are no different for residents of the New Development and Patchwork neighbor-

\footnotetext{
${ }^{6}$ When the Old Urban neighborhoods in New York City are excluded from these models, coefficient estimates have the same directions and significance levels in all three models, with the exception of the Urban Residential neighborhood coefficient in Model A, which is no longer significant.
} 
hood types than for residents of Rural neighborhoods. While living in an Established Suburb, Urban Residential, or Mixed-Use neighborhood appears to have a modest (and negative) effect on the share of SOV trips, the effect of living in an Old Urban neighborhood dwarfs that of living in the other two urban neighborhood types. When we also control for individual factor scores (Model B), Old Urban neighborhoods are the only neighborhood type in which residents have a lower share of trips by SOV than do Rural neighborhood residents. Of the three models, Model B best fits the data (as indicated by the R-squared statistic), and all three models explain about 9 percent of the variation in the share of trips by SOV.

Table 8: Results of Tobit regression models for share of survey-day trips by transit, censored at zero and 100 percent

\begin{tabular}{|c|c|c|c|c|c|c|}
\hline \multirow{3}{*}{$\begin{array}{l}\text { Pseudo } \mathbf{R}^{2} \\
\text { Variable }\end{array}$} & \multicolumn{2}{|c|}{ Model A } & \multirow{2}{*}{\multicolumn{2}{|c|}{$\frac{\text { Model B }}{0.1232}$}} & \multicolumn{2}{|c|}{ Model C } \\
\hline & \multicolumn{2}{|c|}{0.0864} & & & \multicolumn{2}{|c|}{0.1225} \\
\hline & Coefficient & p-value & Coefficient & p-value & Coefficient & p-value \\
\hline \multicolumn{7}{|c|}{ Personal Characteristics } \\
\hline Age & -0.01 & $<0.001$ & -0.01 & 0.002 & -0.01 & 0.002 \\
\hline \multicolumn{7}{|l|}{ Sex (Base: Male) } \\
\hline Female & -0.08 & 0.011 & -0.09 & 0.008 & -0.09 & 0.007 \\
\hline \multicolumn{7}{|c|}{ Racelethnicity (Base: Non-Hispanic White) } \\
\hline Non-Hispanic Black & 0.71 & $<0.001$ & 0.61 & $<0.001$ & 0.60 & $<0.001$ \\
\hline Non-Hispanic Asian & 0.31 & $<0.001$ & 0.14 & 0.090 & 0.14 & 0.080 \\
\hline Hispanic & 0.26 & $<0.001$ & 0.06 & 0.272 & 0.06 & 0.254 \\
\hline Other & 0.41 & $<0.001$ & 0.30 & $<0.001$ & 0.30 & $<0.001$ \\
\hline \multicolumn{7}{|c|}{ Employment (Base: Employed) } \\
\hline Not employed & 0.15 & $<0.001$ & 0.15 & $<0.001$ & 0.15 & $<0.001$ \\
\hline \multicolumn{7}{|l|}{ Internet use (Base: Daily) } \\
\hline Less than daily & 0.19 & $<0.001$ & 0.19 & $<0.001$ & 0.19 & $<0.001$ \\
\hline \multicolumn{7}{|l|}{ Household characteristics } \\
\hline \multicolumn{7}{|c|}{ Education (Base: Less than high school) } \\
\hline High school & -0.38 & $<0.001$ & -0.37 & $<0.001$ & -0.36 & $<0.001$ \\
\hline Some college & -0.43 & $<0.001$ & -0.43 & $<0.001$ & -0.43 & $<0.001$ \\
\hline Four-year degree & -0.31 & $<0.001$ & -0.35 & $<0.001$ & -0.34 & $<0.001$ \\
\hline Graduate degree & $<0.01$ & 0.994 & -0.07 & 0.362 & -0.07 & 0.398 \\
\hline Income $(\$ 10,000 \mathrm{~s})$ & -0.04 & $<0.001$ & -0.04 & $<0.001$ & -0.04 & $<0.001$ \\
\hline Number of $\mathrm{HH}$ adults & -0.01 & 0.682 & 0.01 & 0.777 & $<0.01$ & 0.847 \\
\hline Number of $\mathrm{HH}$ children & -0.13 & $<0.001$ & -0.10 & $<0.001$ & -0.10 & $<0.001$ \\
\hline \multicolumn{7}{|c|}{ Neighborhood characteristics } \\
\hline \multicolumn{7}{|c|}{ Factor scores } \\
\hline Dense & - & - & 0.59 & $<0.001$ & 0.47 & $<0.001$ \\
\hline Diverse & - & - & -0.04 & 0.193 & -0.06 & $<0.001$ \\
\hline Transient & - & - & 0.27 & $<0.001$ & 0.29 & $<0.001$ \\
\hline Established & - & - & 0.17 & $<0.001$ & 0.21 & $<0.001$ \\
\hline Accessible & - & - & 0.35 & $<0.001$ & 0.38 & $<0.001$ \\
\hline \multicolumn{7}{|c|}{ Neighborhood type (Base: Rural) } \\
\hline New development & 0.28 & $<0.001$ & -0.37 & $<0.001$ & - & - \\
\hline Patchwork & 0.63 & $<0.001$ & -0.45 & $<0.001$ & - & - \\
\hline Established suburb & 1.13 & $<0.001$ & -0.37 & $<0.001$ & - & - \\
\hline Urban residential & 1.16 & $<0.001$ & -0.45 & $<0.001$ & - & - \\
\hline Old urban & 2.91 & $<0.001$ & -0.16 & 0.220 & - & - \\
\hline Mixed-use & 1.30 & $<0.001$ & -0.37 & 0.005 & - & - \\
\hline
\end{tabular}

Statistically significant results (at a 95-percent confidence level) in black; non-significant results in grey.

As Table 8 shows, when we control for individual and household characteristics (Model A), neighborhood type is also strongly associated with differences in the share of survey-day transit trips. ${ }^{7}$ Residents of all non-rural neighborhood types made a larger share of survey-day trips by public transit than their rural counterparts, and the effect of living in an Old Urban neighborhood on the share of transit trips is about twice that of living in any other neighborhood type and more than 10 times that of living

${ }^{7}$ When the Old Urban neighborhoods in New York City are excluded from these models, coefficient estimates have the same directions and significance levels in all three models, with the exception of the Old Urban neighborhood coefficient in Model A, which becomes positive and significant. 
in a New Development neighborhood.

Surprisingly, when we also control for individual factor scores (Model B), the effect of neighborhood type on the share of transit trips is still significant for all neighborhood types except Old Urban, but in the opposite direction to that in Model A. This suggests that the interactions between factors such as density, diversity, transience, stability, and accessibility that combine to create each neighborhood type may actually mitigate the effects of individual factors on transit mode shares. This is a notable contrast to the results of our models of PMT, number of trips, and SOV mode shares, which suggest that such interactions intensify the effects of individual factors. When we do not control for neighborhood type (Model C), the magnitude of the effect of the density factor decreases relative to Model B, while the coefficient estimates for the other factors are approximately equal between Model B and Model C. Of the three models, Model B best fits the data (as indicated by the pseudo R-squared statistic). Model A explains about 8 percent of the variation in the share of survey-day trips by transit, and Models $\mathrm{B}$ and $\mathrm{C}$ both explain about 12 percent of this variation.

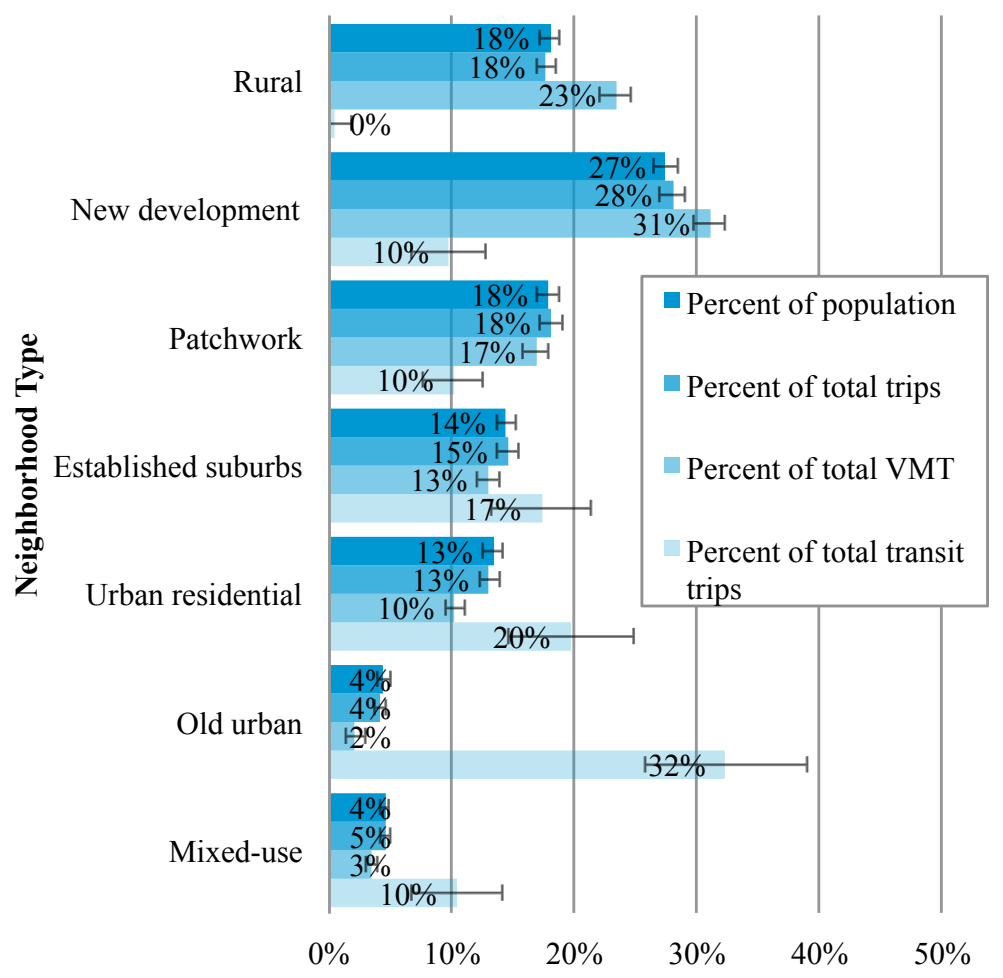

Figure 11: Share of total trips, transit trips, and VMT by neighborhood type

To paint a picture of the relative role each neighborhood type plays in our nation's travel, Figure 11 combines the relative share of each neighborhood type nationwide with three travel behavior descriptors. As shown, the vast plurality of person trips ( 28 percent) and vehicle miles of travel (31 percent) are by residents of the most sprawling of the metropolitan neighborhood types, the New Development neighborhoods. By contrast, over two-thirds (69 percent) of all public transit trips are made by the residents of three neighborhood types (Established Suburb, Urban Residential, and Old Urban) that are home to less than a third (31 percent) of all US residents. The highly spatially asymmetric role of public transit in the nation's travel is cast in even sharper relief by the fact that, despite hosting just one in 25 (4 percent) US residents, Old Urban neighborhoods account for almost one in three (32 percent) of all transit trips. 


\section{$5 \quad$ Conclusions}

Scholars suggest that the observed influence of land-use and urban-form features on travel behavior appears to be relatively modest because such factors do not operate in isolation from one another, but are collective, synergistic, and compounding (Ewing and Cervero 2010; Cervero and Kockelman 1997). We test this hypothesis by characterizing census tracts in the United States into one of seven neighborhood types, based on five land-use and urban-form factors. In doing so, we observe consistent effects between neighborhood type and travel behavior as expected. In addition, we find that, in many cases, these effects persist even when we control for individual built environment characteristics such as density or diversity, suggesting that there are indeed collective, synergistic, and compounding land-use and urban-form effects on travel behavior.

We find that people in rural areas drive more and farther than do people in metropolitan areas. Of all of the metropolitan neighborhood types, travel patterns in New Development neighborhoods, often located on the suburban fringe, are most similar to rural areas. Migrating across neighborhood types, like Burgess' concentric rings for 1920s Chicago, we observe travel patterns that are increasingly "urban" and multi-modal in character. However, in only one of these neighborhood types does private vehicle travel (driving alone and carpooling) account for less than 75 percent of all trips.

Old Urban neighborhoods are very different from the neighborhoods in which most Americans reside, and the travel patterns there are very, very different as a result. At 27.5 dwelling units per acre, the average housing density of an Old Urban neighborhood is nearly eight times greater than the average across all neighborhood types, and public transit service is more than eight times greater than the average level of service across all neighborhood types - the latter of which helps to explain why almost one in three transit trips nationwide are made by Old Urban residents.

Old Urban neighborhoods are not only unique but also comparatively rare. Just 4 percent of the US population resides in Old Urban neighborhoods, compared with 27 percent who live in decidedly auto-centric New Development neighborhoods. Old Urban neighborhoods are, in fact, confined almost exclusively to a few of the largest, most transit-rich metropolitan areas. This asymmetry in the distribution of Old Urban neighborhoods suggests that, as important as residential self-selection may be in the relationship between travel behavior and the built environment, most Americans do not have the opportunity to live in the sorts of neighborhoods where travel is substantially less reliant on private vehicles. Old Urban neighborhoods, and the travel they engender, would seem to be outliers in every sense of the word. Thus, one potential area for future research could be to identify places that have recently evolved into Old Urban neighborhoods (if indeed such places exist) in order to understand the forces behind this evolution.

The minor travel differences observed across all but one of the neighborhood types suggest that modest changes to the built environment being implemented in cities and towns across the United States - slightly higher densities, added mixed-use developments, modest additions to public transit service, and so on-are unlikely to have much effect on travel. Moreover, since the distinctive travel behavior observed in Old Urban neighborhoods appears to be associated with synergistic relationships among individual characteristics of the built environment, simply modifying the built environment along a single dimension is unlikely to achieve the desired effect if the appropriate balance along a variety of other dimensions cannot also be achieved.

Since Old Urban neighborhoods are so strongly associated with less auto-oriented travel behavior, it stands to reason that auto-dependency would decline with an increase in the number of Old Urban neighborhoods. But given their uniqueness, truly extraordinary shifts in the prevailing patterns of urban and suburban development would likely be needed to create more auto-light, Old Urban-type neigh- 
borhoods. Such neighborhoods may well prove attractive to many people because so few of them exist in most metropolitan areas, but creating places that differ so radically from all other urban and suburban neighborhoods will be no easy task. 


\section{References}

Blumenberg, E., B. D. Taylor, M. Smart, K. Ralph, M. Wander, and S. Brumbaugh. 2012. What's Youth Got to Do with It? Exploring the Travel Behavior of Teens and Young Adults. Berkeley, CA: University of California Transportation Center. http://www.uctc.net/papers/UCTC-FR-2012-14.pdf.

Burgess, E. W. 1925. The growth of the city: An introduction to a research project. In The City, edited by Robert E. Park, Ernest W. Burgess, and Roderick D. McKenzie, 1-46. Chicago: The University of Chicago Press.

Cao, X., P. L. Mokhtarian, and S. L. Handy. 2009. Examining the impacts of residential self-selection on travel behavior: A focus on empirical findings. Transport Reviews 29 (3): 359-95. doi:10.1080/01441640802539195.

Cattell, R. B. 1966. The scree test for the number of factors. Multivariate Behavioral Research 1(2): 245-76. doi:10.1207/s15327906mbr0102_10.

Cervero, R., and K. Kockelman. 1997. Travel demand and the 3Ds: density, diversity, and design. Transportation Research Part D: Transport and Environment 2(3): 199-219. doi:10.1016/S13619209(97)00009-6.

Chatman, D. G. 2013. Explaining the immigrant effect on auto use: The influences of neighborhoods and preferences. Transportation 41(3): 441-461. doi:10.1007/s11116-013-9475-4.

Chow, J. 1998. Differentiating urban neighborhoods: A multivariate structural model analysis. Social Work Research 22(3): 131-42. doi:10.1093/swr/22.3.131.

Desgraupes, B. 2013. Clustering Indices. Lab Modal'X, University Paris Oest. https://cran.r-project. org/web/packages/clusterCrit/vignettes/clusterCrit.pdf.

Desgraupes, B. 2014. clusterCrit: Clustering Indices. (Version R package version 1.2.4). http:// CRAN.R-project.org/package=clusterCrit.

Ewing, R., and R. Cervero. 2010. Travel and the built environment. Journal of the American Planning Association 76(3): 265-94. doi:10.1080/01944361003766766.

Federal Highway Administration. 2011. 2009 National Household Travel Survey User's Guide. Washington DC: United States Department of Transportation.

Handy, S., X. Cao, and P. Mokhtarian. 2005. Correlation or causality between the built environment and travel behavior? Evidence from Northern California. Transportation Research Part D: Transport and Environment 10(6): 427-44. doi:10.1016/j.trd.2005.05.002.

Hoyt, H. 1939. The Structure and Growth of Residential Neighborhoods in American Cities. Washington, DC: Federal Highway Administration. http://trid.trb.org/view.aspx?id=131170.

Kaiser, H. F. 1960. The application of electronic computers to factor analysis. Educational and Psychological Measurement 20: 141-51. doi:10.1177/001316446002000116.

Ledesman, R. D., and P. Valero-Mora. 2007. Determining the number of factors to retain in EFA: An easy-to-use computer program for carrying out parallel analysis. Practical Assessment, Research and Evaluation 12(2): 1-11.

Leigh, N. G., and S. Lee. 2005. Philadelphia's space in between: Inner-ring suburb evolution. Opolis 1(1): 12-13. http://escholarship.org/uc/item/16t4c093.

Levine, J., A. Inam, and G.-W. Torng. 2005. A choice-based rationale for land use and transportation alternatives evidence from Boston and Atlanta. Journal of Planning Education and Research 24(3): 317-30. doi:10.1177/0739456X04267714.

Lin, J., and L. Long. 2008. What neighborhood are you in? Empirical findings of relationships between household travel and neighborhood characteristics. Transportation 35(6): 739-58. doi:10.1007/ s11116-008-9167-7. 
Li, Y.-S., and Y.-C. Chuang. 2009. Neighborhood effects on an individual's health using neighborhood measurements developed by factor analysis and cluster analysis. Journal of Urban Health 86(1): 5-18. doi:10.1007/s11524-008-9306-7.

Mikelbank, B. A. 2011. Neighborhood déjà vu: Classification in metropolitan Cleveland, 1970-2000. Urban Geography 32(3): 317-33. doi:10.2747/0272-3638.32.3.317.

Mokhtarian, P. L., and X. Cao. 2008. Examining the impacts of residential self-selection on travel behavior: A focus on methodologies. Transportation Research Part B: Methodological, A Tribute to the Career of Frank Koppelman 42(3): 204-28. doi:10.1016/j.trb.2007.07.006.

Müllner, D. 2013. Fastcluster: Fast hierarchical, agglomerative clustering routines for R and python. Journal of Statistical Software 53(9): 1-18.

Næss, P. 2014. Urban form, sustainability and health: The case of Greater Oslo. European Planning Studies 22(7): 1524-43. doi:10.1080/09654313.2013.797383.

Ramsey, K., and A. Bell. 2014. Smart Location Database, Version 2.0 User Guide. Washington DC: Environmental Protection Agency. http://www2.epa.gov/sites/production/files/2014-03/documents/ sld_userguide.pdf.

Revelle, W. 2014. Psych: Procedures for Personality and Psychological Research. Evanston, IL: Northwestern University. http://CRAN.R-project.org/package=psych Version $=1.4 .5$.

Shay, E., and A. Khattak. 2007. Automobiles, trips, and neighborhood type: Comparing environmental measures. Transportation Research Record 2010 (-1): 73-82. doi:10.3141/2010-09.

Solon, G., S. J. Haider, and J. M. Wooldridge. 2015. What are we weighting for? Journal of Human Resources 50(2): 301-16. doi:10.3368/jhr.50.2.301.

Song, Y., and G.-J. Knaap. 2007. Quantitative classification of neighborhoods: The neighborhoods of new single-family homes in the Portland metropolitan area. Journal of Urban Design 12(1): 1-24. doi:10.1080/13574800601072640.

Song, Y., and R. G. Quercia. 2008. How are neighborhood design features valued across different neighborhood types? Journal of Housing and the Built Environment 23(4): 297-316. doi:10.1007/s10901008-9122-0.

United States Census Bureau. 2010. Decennial Census. Washington DC: U.S. Census Bureau.

Vicino, T. J. 2008. The spatial transformation of first-tier suburbs, 1970 to 2000: The case of metropolitan Baltimore. Housing Policy Debate 1(3): 479-518. doi:10.1080/10511482.2008.9521644.

Winship, C., and L. Radbill. 1994. Sampling weights and regression analysis. Sociological Methods and Research 23(2): 230-57. doi:10.1177/0049124194023002004.

Zhou, B., and K. Kockelman. 2008. Self-selection in home choice: Use of treatment effects in evaluating relationship between built environment and travel behavior. Transportation Research Record 2077(12): 54-61. doi:10.3141/2077-08. 